\title{
Risky decisions and response reversal: is there evidence of orbitofrontal cortex dysfunction in psychopathic individuals?
}

\author{
D.G.V. Mitchell ${ }^{\mathrm{a}, \mathrm{b}}$, E. Colledge ${ }^{\mathrm{a}, \mathrm{b}}$, A. Leonard ${ }^{\mathrm{c}}$, R.J.R. Blair ${ }^{\mathrm{a}, \mathrm{b}, *}$ \\ a Institute of Cognitive Neuroscience, University College London, London, UK \\ ${ }^{\mathrm{b}}$ Department of Psychology, University College London, London, UK \\ ${ }^{\mathrm{c}}$ Department of Psychology, HMP Wormwood Scrubs, London, UK
}

Received 3 September 2001; received in revised form 20 March 2002; accepted 9 April 2002

\begin{abstract}
This study investigates the performance of psychopathic individuals on tasks believed to be sensitive to dorsolateral prefrontal and orbitofrontal cortex (OFC) functioning. Psychopathic and non-psychopathic individuals, as defined by the Hare psychopathy checklist revised (PCL-R) [Hare, The Hare psychopathy checklist revised, Toronto, Ontario: Multi-Health Systems, 1991] completed a gambling task [Cognition 50 (1994) 7] and the intradimensional/extradimensional (ID/ED) shift task [Nature 380 (1996) 69]. On the gambling task, psychopathic participants showed a global tendency to choose disadvantageously. Specifically, they showed an impaired ability to show learning over the course of the task. On the ID/ED task, the performance of psychopathic individuals was not significantly different from incarcerated controls on attentional set-shifting, but significant impairments were found on response reversal. These results are interpreted with reference to an OFC and amygdala dysfunction explanation of psychopathy.
\end{abstract}

Crown Copyright (C) 2002 Published by Elsevier Science Ltd. All rights reserved.

Keywords: Decision-making; Gambling task; Risk; Response inhibition; Intradimensional/extradimensional shift; Response modulation

\section{Introduction}

Psychopathy is a serious developmental disorder characterised by an antisocial lifestyle and reckless behaviour combined with a callous, shallow and manipulative affective-interpersonal style. Psychopathic criminals commit a disproportionate amount of crime, habitually fail to fulfil societal obligations, appear to lack any sense of loyalty, and are unperturbed when confronted with the destructive nature of their behaviour [19,32]. The psychopathy checklist revised (PCL-R) is an empirically valid and reliable instrument for assessing psychopathy in a prison population [31,32]. The PCL-R consists of two factors identified by psychometric analyses [31,35]. Factor one, the affective-interpersonal component, includes items that describe traits central to the classic clinical descriptions of the psychopath; these include callousness and a diminished capacity for guilt, empathy, and remorse. Factor two, the behavioural component, is made up of items that describe traits and behaviours associated with an unstable and antisocial lifestyle; these include impulsiveness, poor behavioural control, and criminal activity.

\footnotetext{
* Corresponding author. Present address: National Institute of Mental Health, 15K North Drive, MSC 2670, Bethesda, MD 20892-2670, USA.

E-mail address: blairj@intra.nimh.nih.gov (R.J.R. Blair).
}

Empirical data provides evidence that psychopathic individuals show a variety of neuro-cognitive abnormalities. Studies have uncovered impairments in fear conditioning [44], startle reflex priming [43], response modulation [47], linguistic processing [70], and autonomic responding to distress cues [15]. Drawing on these findings and others, researchers have suggested that psychopathy is the result of deficits in systems mediating fear $[44,45,50]$, response modulation [46], general affective processing [34], or empathy [9]. However, the individual explanations tend to address only a limited number of phenomena, and despite some overlap, the theories do not explain the entire spectrum of empirical findings and traits associated with the disorder. One means of linking the seemingly disparate results is through the examination of neural substrates that may play a role in the aetiology of psychopathy. Currently, psychopathy is linked to dysfunction in the amygdala [17,51] and the orbitofrontal cortex (OFC) [21,41].

The amygdala, located bilaterally within the temporal lobe, has long been thought to play an important role in emotional processing [42]. The neuro-cognitive deficits consistently demonstrated in psychopathic individuals bear a striking resemblance's to those found in patients with amygdala lesions. For example, psychopathic individuals, like patients with amygdala lesions, show impairments in aversive 
conditioning and reduced potentiation of startle reflex by visual primes $[3,33,40,43]$. Functional imaging studies suggest that the amygdala responds to sad and fearful expressions, but not to those depicting anger or disgust [17,54,55,61]. In accordance, both psychopathic individuals and patients with amygdala lesions show impaired processing of fearful and sometimes sad facial expressions $[1,13,16,25,39,65,66]$.

Other researchers have linked psychopathy to OFC dysfunction. This is primarily motivated by reference to the profound social behavioural disturbance shown by some patients with OFC lesions [18,21]. However, it should be noted that the behavioural disturbance demonstrated by such patients differs from that shown by psychopathic individuals. Patients with OFC lesions frequently show reactive aggression in response to frustration or perceived threat $[2,12,28]$. In contrast, the behaviour of psychopathic individuals is characterised by highly instrumental aggression motivated by material gain or towards establishing respect [20,69]. Despite this caveat, there are some empirical indications of OFC pathology in psychopathic individuals. Using a Go/No-Go task in which participants were required to inhibit a learned prepotent response, Lapierre et al. [41] found that psychopathic individuals made more commissive errors than comparison individuals. Furthermore, psychopathic individuals have been found to show impaired extinction of previously rewarding responses in a single-pack card playing task [47]. Considerable human and animal data suggests that the OFC is involved in altering previously acquired stimulus-reward associations when they become inappropriate $[23,58]$. Thus, patients with OFC lesions, like psychopathic individuals, have difficulty altering a previously rewarding response in favour of a previously punishing response when the reward contingencies are unexpectedly reversed [56,59].

Another form of task that is sensitive to OFC dysfunction is the four-pack gambling task developed by Bechara et al. $[5,6]$. In this task, participants choose from four decks of cards each with different rates of monetary reinforcement. Two of the decks contain high rewards, but even higher punishment making them disadvantageous. The other two decks have low reward, but even lower punishment values. Over the course of the task, healthy participants show a preference for the low-risk decks whereas patients with lesions to the OFC continue to choose disadvantageously $[2,5]$. Two studies have found psychopathic adults to perform similarly to comparison groups on the gambling task $[60,12]$. However, the studies contained significant procedural differences from those presented by Bechara et al. [8]. Furthermore, in a recent study using identical instructions to those of Bechara et al. [6], Blair et al. found that the performance of boys with psychopathic tendencies on the gambling task was impaired relative to a comparison group [14].

The current study investigates the performance of psychopathic individuals on two tasks thought to be sensitive to OFC dysfunction: the gambling task and the intradimensional/extradimensional shift (ID/ED) task. A previous study has suggested that both patients with amygdala lesions and those with damage to the OFC show impaired performance on the gambling task [6]. In contrast, the ID/ED task is thought to index two dissociable functions of the frontal cortex. In addition to indexing response reversal performance, the task also includes a separate ED set-shift component requiring the participant to attend to some aspect of the stimulus that did not predict reward or punishment on earlier trials. Whereas impaired response reversal performance is associated with lesions of the OFC [56,58,59], extra-dimensional shift dysfunction is associated with damage to the dorsolateral prefrontal cortex [50,23]. Moreover, these abilities to perform extra-dimensional shifts have been shown to be clearly doubly dissociable in both animal lesion studies as well as human neuropsychological work [23,50,56,58,59].

If psychopathic individuals present with OFC dysfunction, it can be predicted that they should present with impaired performance on both the gambling task and response reversal components of the ID/ED, but intact performance on the ED shift component. The current study tests these predictions.

\section{Method}

\subsection{Participants}

Participants were 51 men selected from three category B (high security) forensic institutions in the London area. Files were pre-screened to exclude individuals who were older than 50 or whose psychiatric reports revealed a diagnosis for psychosis, organic brain damage, or neurological disorder. It was explained that participation was voluntary, and would not affect individual status or record within the institution. Participants did not receive any financial or other gain for their participation or performance on any of the tasks.

Although a total of 51 inmates participated in the study, not all individuals were available for two testing sessions due to inmate transfers. Consequently, 31 adults took part in both tasks, nine completed only the gambling task and 11 completed only the ID/ED task. The ages of the participants ranged from 21 to 50 with a mean of 33.06 years (S.D. = 8.03). The mean age for psychopathic and non-psychopathic groups was 34.42 (S.D. = 8.07) and 31.64 (S.D. = 7.91), respectively. The Raven's advanced progressive matrices was administered to provide an estimate of intelligence. Raven's scores ranged from 4 to 12 with a mean of 8.12 (S.D. $=2.47$ ). The mean Raven's advanced matrix group scores for psychopathic and control groups was 7.65 (S.D. = 2.40 ) and 8.60 (S.D. $=2.50$ ), respectively (according to UK norms, a score of nine is equivalent to the 50th percentile for individuals aged 28-32; Ravens, 1994). There were no significant group differences in either age $F(1,49)=1.55$, ns, or Ravens score $F(1,49)=1.90$, ns. The sample was made up of 49 Caucasian and two Afro-Caribbean participants (one Afro-Caribbean participant in each group). In order to confirm that the groups were age and cognitively matched 
Table 1

Participant characteristics S.D. and ranges in () brackets

\begin{tabular}{lrr}
\hline Group & PCL-R & Age \\
\hline The gambling task & $33.10(2.22 ; 30-37.5)$ & $34.90(7.06 ; 22-47)$ \\
$\quad$ Psychopathic inmates $(n=20)$ & $8.65(2.88 ; 4.5-14)$ & $30.35(7.41 ; 21-44)$ \\
Controls $(n=20)$ & & $3.65(2.48 ; 4-12)$ \\
The ID/ED task (primary analysis) & $33.07(2.29 ; 30-37)$ & $32.67(7.69 ; 22-50)$ \\
Psychopathic inmates $(n=15)$ & $9.16(3.50 ; 4.5-14)$ & $7.73(2.22 ; 4-12)$ \\
Controls $(n=17)$ & & $8.65(2.67 ; 4-12)$ \\
ID/ED task (all participants $)$ & $32.98(2.16 ; 30-37.00)$ & $33.62(8.01 ; 22-50)$ \\
$\quad \begin{array}{l}\text { Psychopathic inmates }(n=21) \\
\text { Controls }(n=21)\end{array}$ & $9.08(3.24 ; 4.5-14)$ & $32.86(7.93 ; 22-45)$ \\
\hline
\end{tabular}

for the reduced number of participants involved in the ID/ED and gambling task primary analyses, additional one-way ANOVAs were conducted on age and Raven's score. These revealed that the mean age and Raven's score did not differ significantly between groups for either task. Please see Table 1 for participant means, standard deviations and ranges divided by task.

\subsection{Measures}

\subsubsection{The PCL-R [31]}

The PCL-R consists of 20 behavioural items that are scored on the basis of a file review and semi-structured interview. High interrater reliability coefficients for total scores (not <0.83) and high Cronbach alpha coefficients and inter-item correlations provide support that the PCL-R is a valid and reliable device for assessing psychopathy in a forensic hospital or prison setting. In accordance with the literature and the guidelines of the PCL-R, the psychopathic group for the current study was composed of individuals with a PCL-R score of 30 or above, while the non-psychopathic group was made up of individuals scoring $<20$. Individuals scoring in the middle range on the PCL-R were also excluded as, although containing some elements of psychopathy, these individuals do not meet criteria for either psychopathic or non-psychopathic groups [31]. After consent was obtained, participants were interviewed. Participants who declined an interview, but were willing to participate in the experiment $(n=6)$, were scored according to file notes. Evidence suggests that the PCL-R can be scored on a reliable and valid basis if detailed file information is available [31,71]. Interrater reliability was established by means of a Spearman rank correlation conducted on 41 inmates who were scored independently by two raters. The correlation, ranks $=0.89(P<$ $0.01)$, is comparable to that presented in the literature [31].

The gambling task $[5,6]$ The gambling task was administered in computerised format with a schedule of reinforcement described in Bechara et al. [6]. In brief, the task consists of a card game in which participants make selections from four decks $(A, B, C$, and $D)$ presented on a computer screen. Each deck contained different rates and values of monetary reinforcement (play money). With each selection, the computer emitted a distinct sound (similar to a casino slot machine). Subsequently, a message was displayed on the screen indicating the amount of money the participant had won or lost, and a green bar located above the decks changed proportionately according to the result. The minimum inter-trial interval between selections was set at $1 \mathrm{~s}$. The task consisted of 100 trials (card selections), after which, the program shut off automatically. The participant was not informed in advance about the total number of trials.

On the screen, the backs of the cards appeared identical, like real decks of cards. Decks $A$ and $C$ have a higher frequency of punishment, but these punishments are of a lower magnitude. Decks $B$ and $D$ have a lower frequency of punishment, but the punishments are of a higher magnitude. Overall, decks $A$ and $B$ are disadvantageous and will result in a sizeable net loss. Over the course of ten selections from $\operatorname{deck} A$, the participant gains US\$1000, but there are also five unpredictable losses ranging from US\$ 150 to 350 thereby bringing the total loss to US $\$ 1250$. Over 10 selections from deck $B$, the participant gains US\$ 1000 , but there is one loss of US\$1250. In contrast, decks $C$ and $D$ are advantageous, rendering a net gain. Decks $C$ and $D$ enable a gain of US\$ 500, but even smaller losses (ranging from US\$ 25 to 75 in deck $C$ and one US\$ 250 loss in deck $D$ ) thereby rendering a net gain of US\$250. The instructions given are identical to those detailed in Bechara et al. [6]. Participants are told that they are free to choose from any of the decks that they wish, and that the objective is to win as much money as possible or to avoid losing as much as possible. In this version of the instructions, it is made explicit that some decks are worse than others, and that it is possible to achieve the game objectives if these poor decks are avoided. As with previous studies incorporating the gambling task, the task was split up into five blocks of 20 trials $[5,6,60]$, and the dependent variable was the number of disadvantageous selections made in each block.

\subsubsection{The ID/ED Task [23]}

The ID/ED is a multi-component instrumental learning task. Participants learn to select between two stimuli presented to them on a computer screen based on feedback provided on the display (the words 'correct' or 'incorrect'). The 
stimuli presented are novel, and involve up to two dimensions (object shape and line contour). The correct stimulus for a discrimination is always specified by one dimension or the other (i.e. shape one whether it is pared with line one or line two; or line one regardless of the shape that it is paired with).

On each trial, the two test stimuli appeared randomly in two of four rectangles positioned towards the perimeter of the screen. In order to make a selection, participants used a mouse to position the cursor over the box containing the relevant stimulus. The task consists of nine stages presented in fixed order, and participants were required to demonstrate having learnt the given discrimination before proceeding past a given stage. In order to meet the discrimination learning criterion, participants were required to choose the correct stimulus on eight consecutive trials. Participants did not receive any notification when a block ended, and a new rule was to be learned. Nor were they told how many trials or phases made up the experiment. The nine stages and their descriptions are:

1. Simple discrimination: between two (pink) shapes (shape one and shape two). The participant must learn to respond to shape one.

2. Simple reversal: contains the same two stimuli, but the reward contingencies are reversed. Thus, the participant must inhibit responding to shape one and instead respond to shape two.

3. Compound discrimination-separate: a pair of white line patterns is introduced (line one and line two). However, the contingencies remain unchanged. The participant should maintain responding to shape two whether shape two is paired with line one or line two. The pink shapes and white line are kept separate to encourage the subject to perceive them as distinct. Pairing is pseudo-random: the same pairings (e.g. shape one-line one and shape two-line two) appear in runs of no more than three trials.

4. Compound discrimination superimposed: the white lines are superimposed on the pink forms for this and all subsequent stages, so that transfer learning could not be attributed to spatial learning. The contingencies remain the same. The participant should maintain responding to shape two.

5. Compound reversal: the same stimuli are used but the contingencies are reversed. The participant must reverse their selection of shape two and respond to shape one. The lines remain without predictive power for reward.

6. Intra-dimensional shift: new shapes and lines are introduced (shape three and shape four and line three and line four). The participant must learn to select shape three whether it is paired with line three or line four.

7. Intra-dimensional reversal: the contingencies are reversed. The participant must inhibit the selection of shape three and respond to shape four.

8. Extra-dimensional shift: new shapes and lines are again introduced (shape five with shape six; line five with line six). However, in this phase of the task the participant must learn that the lines are the stimulus features that predict reward rather than shape. Thus, the participant must learn to select line five whether it is paired with shape five or shape six.

9. Extra-dimensional reversal: the contingencies are reversed. The participant must inhibit selecting line five in favour of responding to line six.

10. The dependent variable was defined as the number of errors made before successfully advancing to the next stage (calculated by the computer). In the event that an individual was unable to pass a given stage, the task was terminated.

\section{Procedure}

Each participant was tested individually in a quiet interview room on the wing. Both the gambling and ID/ED tasks were presented as part of a larger neuropsychological test battery delivered in random order. The tasks were described without informing the participant of the investigation's specific objectives and expectations.

\section{Results}

\subsection{The gambling task}

Based on previous reports in the literature $[5,6]$, we predicted that controls would sample randomly at first, but then develop a preference for the advantageous decks. In contrast, we predicted that psychopathic inmates would fail to show risk-aversive behaviour throughout the task. Accordingly, we predicted a significant group-block interaction with psychopathy being associated with sustained high-risk deck selections. For the analysis, we divided the 100 trials into five blocks of 20 trials each. For each block we calculated the number of disadvantageous selections (decks $A$ and $B$ ), as well as the number of advantageous selections (decks $C$ and $D$ ). The performance of the two groups is presented in Fig. 1. The analysis was conducted by way of a mixed-model ANOVA. Due to the fact that Mauchly's test of sphericity showed a heterogeneity of covariance, the more conservative Greenhouse-Geisser test was performed. The resulting 2 (control versus psychopathic) $\times 5$ (blocks of 20 trials) ANOVA yielded main effects for block, $(F(2.82,107.03)=$ 4.40; $P<0.01$ ), with participants becoming increasingly risk-aversive over time. There was also an effect for Group, with non-psychopathic individuals making fewer selections from the disadvantageous decks than psychopathic participants $(F(1,38)=6.14 ; P<0.05)$. The block-group interaction was also significant $(F(2.82,107.03)=2.56$; $P<0.05$; one-tailed); non-psychopathic individuals became more risk-aversive over time compared with psychopathic participants (see Fig. 1). An examination of block by 
Gambling Task Results

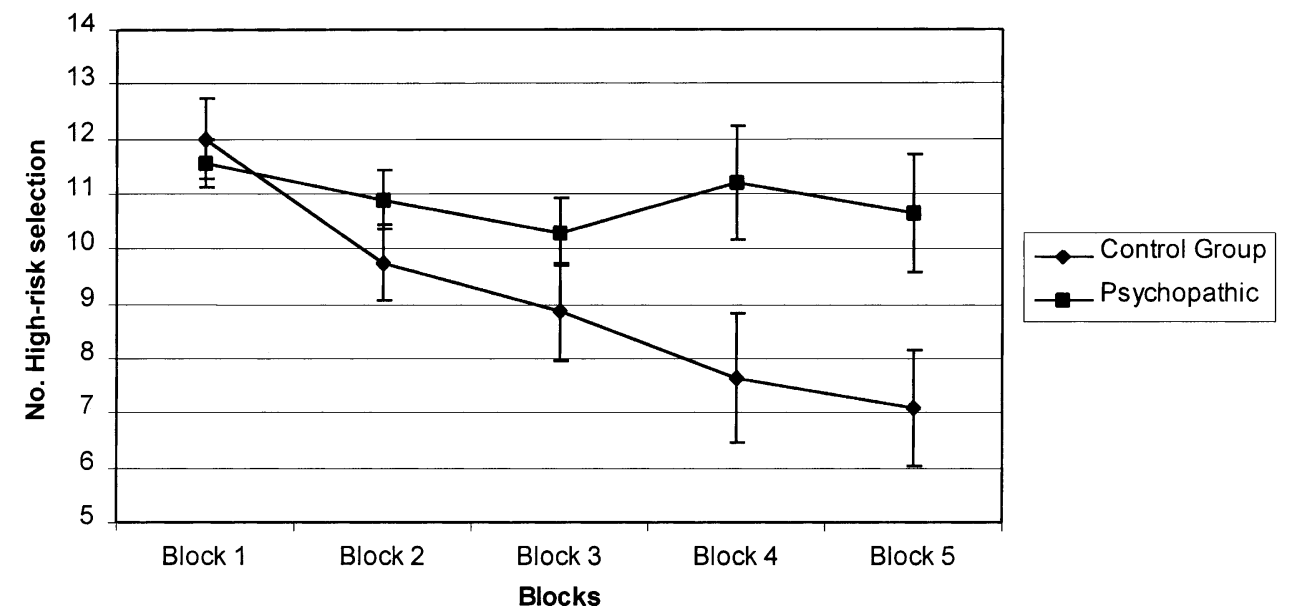

Fig. 1. The mean number of high-risks elections of psychopathic and non-psychopathic individuals across five blocks of 20 trials. Psychopathic individuals showed reduced risk aversion over the course of the task relative to the comparison group: (points) represent the mean number of selections from the risky decks per 20 selections; (vertical lines) depict S.E.M.

block performance by group in light of the interaction suggests that the main effect for block may best be accounted for by the performance of the control group.

\section{2. $I D / E D$}

The mean number of errors for each of the three core stage types was calculated for psychopathic and non-psychopathic inmates (Table 2). The three core stage types were: learning (phases 1 and 6), reversal learning (phases 2, 5, 7, 9), and extra-dimensional shifting (phase 8). Because obtaining a reliable mean was contingent upon passing all stages, only those participants who had successfully completed each stage were included in the primary analysis. A failure was defined as the commission of 16 errors without achieving the criterion for passing (eight consecutive correct choices). The exception was one psychopathic individual, who after making 12 errors on the ED portion of the task, elected to terminate the experiment. As six psychopathic and four control individuals failed to complete the ED-shift component of the study, the sample included in the primary analysis was 32 (15 psychopathic and 17 non-psychopathic individuals). Based on previous reports investigating the performance of psychopathic individuals on tasks associated

Table 2

Performance of participants on the ID/Ed task on each phase

\begin{tabular}{|c|c|c|c|c|}
\hline \multirow[t]{2}{*}{ Phase } & \multicolumn{2}{|c|}{ Psychopathic $(n=21)$} & \multicolumn{2}{|c|}{ Non-psychopathic $(n=21)$} \\
\hline & Mean errors (S.D.) & Number of failures & Mean errors (S.D.) & Number of failures \\
\hline (1) Simple & 1.00 & 0 & 0.57 & 0 \\
\hline discrimination & $(3.26)$ & - & $(1.36)$ & - \\
\hline \multirow[t]{2}{*}{ (2) Simple reversal } & $3.10^{*}$ & 0 & 0.86 & 0 \\
\hline & $(3.81)$ & - & - & $(1.24)$ \\
\hline (3) Compound & 0.62 & 0 & 0.86 & 0 \\
\hline discrimination & $(0.86)$ & & $(1.59)$ & \\
\hline (4) Compound & 0.29 & 0 & 0.14 & 0 \\
\hline discrimination & $(0.72)$ & & $(0.48)$ & \\
\hline superimposed & - & - & - & - \\
\hline (5) Compound & 0.29 & 0 & 0.29 & 0 \\
\hline reversal & $(0.56)$ & & $(0.78)$ & \\
\hline \multirow[t]{2}{*}{ (6) ID shift } & 0.14 & 0 & 0.19 & 0 \\
\hline & $(0.36)$ & & $(0.51)$ & \\
\hline \multirow[t]{2}{*}{ (7) ID shift reversal } & 0.24 & 0 & 0.24 & 0 \\
\hline & $(0.54)$ & - & $(0.70)$ & - \\
\hline \multirow{2}{*}{ (8) ED shift } & 8.00 & 6 & 5.33 & 4 \\
\hline & $(6.66)$ & & $(6.07)$ & \\
\hline \multirow[t]{2}{*}{ (9) ED shift reversal } & $3.94^{*}$ & 0 & 0.29 & 0 \\
\hline & $(5.96)$ & - & $(0.47)$ & - \\
\hline
\end{tabular}

${ }^{*} P<0.05$ 
ID / ED Task Results

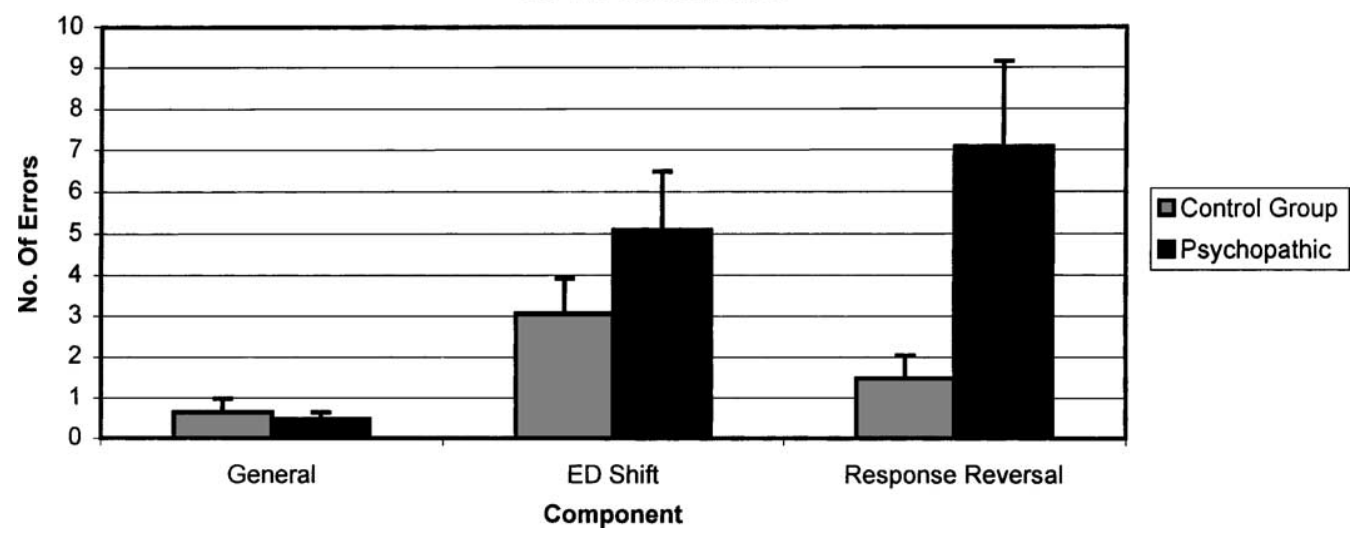

Fig. 2. The mean number of errors made by psychopathic and non-psychopathic individuals across key components of the ID/ED task. Psychopathic individuals made significantly more errors than the comparison group only on the response reversal component: (points) represent the number of errors; (vertical lines) indicate the S.E.M.

with response reversal and extinction [41,47], we predicted that psychopathic participants would show impaired performance on the response reversal component of the task. In contrast, based on evidence in the literature suggesting that psychopathic individuals do not show impairments on attentional set-shifting as indexed by measures such as the Wisconsin Card-sorting task [30,41], we predicted that psychopathic individuals would not show impairments on the ED component of the task relative to non-psychopathic individuals.

The two groups were initially compared using a 2 (psychopathic versus non-psychopathic individuals) $\times 3$ (component: learning, reversal learning and extra-dimensional shift) mixed-model ANOVA. Mauchly's test of sphericity was significant (Mauchly's $W=0.760$; d.f. $=$ 2; $P<0.05$ ); consequently, the more conservative Greenhouse-Geisser test was used for the analysis. This revealed a significant main effect for component $(F(1.61,48.37)=7.75 ; P<0.01)$ with participants making fewest errors on the learning component of the task (see Fig. 2). A significant main effect for group revealed $(F(1,30)=7.86 ; P<0.01)$ that psychopathic individuals made more errors on the task than the comparison group. A significant group by component interaction also emerged, $(F(1.61,48.37)=3.63 ; P<0.05)$; psychopathic individuals made the greatest number of errors on the reversal component whereas non-psychopathic individuals made the greatest number of errors on the ED component.

To determine how selective the effect for group was on the components of interest, three one-way ANOVAs were conducted comparing the performance of psychopathic individuals and controls on learning, response reversals, and ED shifts. The results showed that psychopathic inmates made significantly more errors on the response reversal components $(F(1,30)=7.11 ; P<0.05)$. In contrast, no significant differences were found for performance on the learning component $(F(1,30)=0.218$; ns $)$, or the $\mathrm{ED}$ component $(F(1,30)=2.02 ; \mathrm{ns})$.

Although a non-significant difference existed between the two groups on the number of errors committed on the ED component, ten participants failed to complete this component, and were subsequently omitted from the primary analysis. We elected to further analyse the level of ED dysfunction in two ways. First, we conducted a one-way ANOVA which included participants who had failed the ED component of the task (made 16 errors at which point the task was terminated). This revealed no significant group differences related to the number of errors committed on the ED component of the task $(F(1,40)=1.84$; ns). Second, in order to assess whether psychopathic individuals were disproportionately represented in this subset of individuals failing the ED component, we conducted a Chi-square. The results indicate that the percentage of psychopathic versus non-psychopathic participants failing the ED component of the task was not significantly different $\left(\chi^{2}(1)=\right.$ $0.525 ; \mathrm{ns})$.

\section{Discussion}

The role of this study was to examine the performance of adult psychopathic individuals on the gambling and ID/ED tasks. In line with predictions, psychopathic individuals were less likely to avoid making risky selections over the course of the gambling task relative to comparison individuals. With regard to the ID/ED task, psychopathic individuals showed a selective response reversal deficit while performing similarly to control participants on the attentional set-shifting and learning components of the task. Furthermore, this selective result can not be attributed to a task difficulty effect; a significant interaction revealed that while the psychopathic individuals made more errors on the response reversal components of the task than the attentional set-shifting 
component, the opposite was true for the comparison group.

A previous study has suggested impaired response reversal performance in psychopathic adults [41]. The present study provides additional evidence for this impairment. However, it is worth noting that a recent study investigating boys with psychopathic tendencies found intact performance for simple response reversal [16]. With regard to the gambling task, two studies have reported non-significant differences between psychopathic and comparison groups $[12,60]$. However, the procedure of both studies differed significantly from those of Bechara et al. [6]. In particular, the instructions used did not explicitly state that some decks involved more loss than others, and that participants could win more money overall if they avoided those decks. This may have created a tendency for participants to approach the task as one of chance thereby reducing the influence of signals generated in response to reward contingencies. The only two studies that used the instructions of Bechara et al. [6] indicate a different result. Thus, both boys with psychopathic tendencies [14], and psychopathic adults in the current study show a significantly reduced tendency to shift responding from the risky decks relative to their respective comparison groups.

One way of conceptualising deficits associated with OFC dysfunction is in light of the somatic marker hypothesis $[21,22]$. The hypothesis suggests that during decisions of emotional significance, bio-regulatory states provide affective colouring to available response options either through bodily feedback ('body loop'), or by representations of bodily feedback formed from previous associations ('as-if body loop'). Effectively, the somatic marker labels an option as either good or bad, thereby rapidly constraining the incentive value of that particular choice. Damasio and co-worker [2] and Damasio et al. [21,22] suggest that dysfunction in the somatic marker system may give rise to psychopathic characteristics. Although the behavioural data in the current study is consistent with the somatic marker hypothesis, the explanation does not predict important findings associated with developmental psychopathy. For example, one of the key findings with respect to the somatic marker hypothesis is that individuals with OFC lesions show reduced autonomic responding to emotionally arousing stimuli [22]. In contrast, psychopathic adults and boys with psychopathic tendencies show a selective impairment to stimuli depicting sad or fearful expressions, and show intact responding to other emotional stimuli such as threat cues $[4,10,11,37,52]$. In light of these contradictions, it seems unlikely that developmental psychopathy can be explained strictly in terms of somatic marker dysfunction.

It should be noted that the present study has clear significance for another important model of psychopathy, the response modulation hypothesis. Response modulation is defined as a "rapid and relatively automatic (i.e. non-effortful or involuntary) shift of attention from the effortful organisation and implementation of goal-directed behaviour to its evaluation" $[46,48,53]$. The suggestion is that dysfunction in this system results in a failure to give sufficient consideration to potentially relevant peripheral information when engaging in goal-directed behaviour. Data from the one-pack card playing task supports the model's prediction that psychopathic individuals should persist in responding to a previously rewarded response, even if the rate of punishment increases $[26,47,49]$. However, evidence from lesion studies do not support the idea of an unitary system for response modulation $[23,56,59]$. These studies show a double dissociation between the system crucial for response reversal and the system crucial for attentional set-shifting. Both response reversal and attentional set-shifting are clear examples of a modulation in responding. Response reversal requires participants to redirect their attention from one stimulus to another. The attentional set-shifting component requires individuals to re-direct their attention from one stimulus dimension (shape), in favour of another (superimposed design). Thus, the neuropsychological data clearly demonstrate that there is no single system for response set modulation. This conclusion is supported by the current study. The psychopathic individuals presented with poor response reversal performance. However, they did not show deficits in performing attentional shifts in the current study, nor is there evidence of deficits on attentional set-shifting using the Wisconsin Card-sorting task $[30,41]$. This suggests that the response modulation hypothesis is in need of modification to clarify the parameters under which the system is thought to operate.

An alternative way of conceptualising the current results is in light of the interconnections between the basolateral amygdala and the OFC. The amygdala is involved in the formation of stimulus-reinforcement associations [38,42,62]. The OFC is involved in encoding motivational significance of cues and the incentive value of expected outcomes and is particularly important for appropriate responding when reinforcement contingencies change $[27,58,63,67]$. A circuit consisting of both structures is thought to play a crucial role in encoding and implementing associative information about the motivational significance of stimuli $[27,62,63]$. For example, Baxter et al. [24] found that rhesus monkeys that underwent surgical disconnection of the amygdala and OFC were unable to adjust their choice behaviour after a reduction in the value of a reinforcer. In accordance with an integrated circuit explanation, imaging results show a strong response signal in the amygdala to this component on a variant of the ID/ED task (Rogers, personal communication). An integrated circuit hypothesis would explain why patients with OFC or amygdala lesions show impaired performance on the gambling task $[5,6]$, and why both the amygdala and OFC is implicated in brain imaging results during the performance of the task [29].

The suggestion must be that the degree of dysfunction in this circuit determines the degree of response reversal performance decrement on such tasks as the gambling and ID/ED tasks. Boys with psychopathic tendencies may have 
less dysfunction than the adults as indicated by delayed risk avoidance learning relative to comparison boys, but intact performance on the ID/ED relative to comparison groups. In contrast, the greater dysfunction in psychopathic adults is shown by the lack of risk avoidance learning on gambling task and the pronounced response reversal impairment on the ID/ED task. The differences in the degree of OFC impairment between adults and boys with psychopathic tendencies may be a developmental consequence of the disorder. Given the evidence for interdependence and functional connectivity of the OFC and amygdala, it is possible that a primary deficit within the amygdala could give rise to deficits associated with OFC impairment. Indeed, a recent imaging study shows reduced amygdalar volume in psychopathic individuals relative to a comparison group [68]. Although highly speculative, a reduction in afferent input from the amygdala may, over time, have a negative impact on the responsiveness of the OFC. Accordingly, the long-term effects of this dysfunction may not be as apparent until later in the life-span. This would account for the apparent absence of response reversal deficits in boys with psychopathic tendencies.

Alternatively, the greater impairment seen in adult psychopathic individuals may arise as a secondary consequence of the behavioural characteristics of the disorder. For example, one of the criteria of psychopathy, stimulation seeking, is often associated with drug use [31]. Studies suggest that psychopathy is associated with higher rates of drug abuse, dependence, and poly-drug use [36,64]. Crucially, studies also show impaired performance on the gambling task in alcohol and drug dependent individuals [7,29]. Using a novel decision-making task, Rogers et al. [57] assessed the quality of decision-making and deliberation time of individuals with focal OFC damage, and individuals who abused amphetamine or opiates. All three groups showed impaired performance on the task relative to comparison groups. Given the neuro-cognitive impairments associated with chronic drug abuse, and the data suggesting higher rates of abuse and dependence among psychopathic individuals, we cannot discount the possibility that some of the decision-making impairments seen in psychopathic individuals is acquired as a secondary consequence of the stimulus seeking behaviour associated with the disorder.

The current study provides evidence for impaired performance of psychopathic individuals on the gambling task and the response reversal component of the ID/ED task. This impairment may be representative of a dysfunction within a neural circuit including the amygdala and OFC that is crucial for the motivational value of stimuli. This finding is consistent with other studies that assess psychopathic individuals on tasks with response reversal, or response modulation components [41,47]. However, evidence suggests that this dysfunction is greater than that seen in boys with psychopathic tendencies [14]. This discrepancy raises the possibility that OFC deficits observed in adult psychopathic individuals may develop as a secondary consequences of early amygdala dysfunction. Further research that controls for substance abuse history, and includes decision-making tasks with graded levels of difficulty may provide additional evidence.

\section{Acknowledgements}

This work was supported by a Medical Research Council grant (reference G9716841) and the Department of Health (VISPED initiative). The authors would like to thank the staff at HMP Wormwood Scrubs for their assistance.

\section{References}

[1] Adolphs R, Tranel D, Young AW, Calder AJ, Phelps EA, Anderson AK, et al. Recognition of facial emotion in nine individuals with bilateral amygdala damage. Neuropsycholgia 1999;37:1111-7.

[2] Anderson SW, Bechara A, Damasio H, Tranel D, Damasio AR. Impairment of social and moral behavior related to early damage in human prefrontal cortex. Nature Neuroscience 1999;2:1032-7.

[3] Angrilli A, Mauri A, Palomba D, Flor H, Birhaumer N, Sartori G, et al. Startle reflex and emotion modulation impairment after a right amygdala lesion. Brain 1996;119:1991-2000.

[4] Aniskiewicz AS. Autonomic components of vicarious conditioning and psychopathy. Journal of Clinical Psychology 1979;35:60-7.

[5] Bechara A, Damasio AR, Damasio H, Anderson SW. Insensitivity to future consequences following damage to human prefrontal cortex. Cognition 1994;50:7-15.

[6] Bechara A, Damasio H, Damasio AR, Lee GP. Different contributions of the human amygdala and ventromedial prefrontal cortex to decision-making. Journal of Neuroscience 1999;19:5473-81.

[7] Bechara A, Dolan S, Denburg N, Hindes A, Anderson SW, Nathan PE. Decision-making deficits, linked to a dysfunctional ventromedial prefrontal cortex, revealed in alcohol and stimulant abusers. Neuropsychologia 2001;39:376-89.

[8] Bechara A, Tranel D, Damasio H. Characterization of the decisionmaking deficit of patients with ventromedial prefrontal cortex lesions. Brain 2000;123:2189-202.

[9] Blair RJR. A cognitive developmental approach to morality: investigating the psychopath. Cognition 1995;57:1-29.

[10] Blair RJR. Moral reasoning in the child with psychopathic tendencies. Personality and Individual Differences 1997;22:731-9.

[11] Blair RJR. Responsiveness to distress cues in the child with psychopathic tendencies. Personality and Individual Differences 1999;27:135-45.

[12] Blair RJR, Cipolotti L. Impaired social response reversal: a case of "acquired sociopathy". Brain 2000;123:1122-41.

[13] Blair RJR, Coles M. Expression recognition in early adolescence. Cognitive Development 2000;15:421-34.

[14] Blair RJR, Colledge E, Mitchell DGV. Somatic markers and response reversal: is there orbitofrontal cortex dysfunction in boys with psychopathic tendencies. Journal of Abnormal Child Psychology 2001;29:499-511.

[15] Blair RJR, Jones L, Clark F, Smith M. The psychopathic individual: a lack of responsiveness to distress cues? Psychophysiology 1997;34:192-8.

[16] Blair RJR, Mitchell DGV, Colledge E, Leonard RA, Shine JH, Murray LK, Perrett DI. Reduced sensitivity to other's fearful expressions in psychopathic individuals, submitted for publication.

[17] Blair RJR, Morris JS, Frith CD, Perrett DI, Dolan R. Dissociable neural responses to facial expressions of sadness and anger. Brain 1999;122:883-93. 
[18] Blumer D, Benson DF. Personality changes with frontal and temporal lobe lesions. In: Benson DF, Blumer D, editors. Psychiatric aspects of neurological disease. New York: Grune \& Stratton, 1975. p. 151-70.

[19] Cleckley H. The mask of sanity. St Louis, MO: Mosby, 1967.

[20] Cornell DG, Warren J, Hawk G, Stafford E, Oram G, Pine D. Psychopathy in instrumental and reactive violent offenders. Journal of consulting and clinical psychology 1996;64:783-90.

[21] Damasio AR. Descartes' error: emotion, rationality and the human brain. New York: Putnam (Grosset Books) 1994.

[22] Damasio AR, Tranel D, Damasio H. Individuals with sociopathic behaviour caused by frontal damage fail to respond autonomically to social stimuli. Behavioural Brain Research 1990;41:81-94.

[23] Dias R, Robbins TW, Roberts AC. Dissociation in prefrontal cortex of affective and attentional shifts. Nature 1996;380:69-72.

[24] Baxter MG, Parker A, Linder CCC, Izquierdo AD, Murray EA. Control of response selection by reinforcer value requires interaction of amygdala and orbital prefrontal cortex. The journal of Neuroscience 2000;20:4311-19.

[25] Fine C, Blair RJR. Mini review: the cognitive and emotional effects of amygdala damage. Neurocase 2000;6:435-50.

[26] Fisher L, Blair RJR. Cognitive impairment and its relationship to psychopathic tendencies in children with emotional and behavioural difficulties. Journal of Abnormal Child Psychology 1998;26:511-9.

[27] Gallagher M, McMahan RW, Schoenbaum G. Orbitofrontal cortex and representation of incentive value in associative learning. Journal of Neuroscience 1999;19:6610-4

[28] Grafman J, Schwab K, Warden D, Pridgen BS, Brown HR. Frontal lobe injuries, violence, and aggression: a report of the vietnam head injury study. Neurology 1996;46:1231-8.

[29] Grant S, Contoreggi C, London ED. Drug abusers show impaired performance in a laboratory test of decision-making. Neuropsychologia 2000;38:1180-7.

[30] Hare RD. Performance of psychopaths in cognitive tasks related to frontal lobe function. Journal of Abnormal Psychology 1984;93:13340.

[31] Hare RD. The Hare psychopathy checklist-revised. Toronto, Ontario: Multi-Health Systems, 1991.

[32] Hare RD. Psychopathy, affect and behavior. In: Cooke DJ, Forth AE, Hare RD. editors, Psychopathy: theory, research and implications for society. Dordrecht, The Netherlands: Kluwer, 1998. p. 81-105.

[33] Hare RD, Quinn MJ. Psychopathy and autonomic conditioning. Journal of Abnormal Psychology 1971;77:223-35.

[34] Hare RD, Williamson SE, Harpur TJ. Psychopathy and language. In: Moffitt TE, Sarnoff AM, editors. Biological contributions to crime causation. NATO advanced science series D: behavior and social sciences. Dordrecht, The Netherlands: Martinus Nishoff Publishing, 1988. p. 68-92.

[35] Hart SD, Forth AE, Hare RD. Performance of criminal psychopaths on selected neuropsychological tests. Journal of Abnormal Psychology 1990;99:374-9.

[36] Hemphill JF, Hart SD, Hare RD. Psychopathy and substance use. Journal of Personality Disorders 1994;8:169-80.

[37] House TH, Milligan WL. Autonomic responses to modeled distress in prison psychopaths. Journal of Personality and Social Psychology 1976;34:556-60.

[38] Killcross S, Robbins TW, Everitt BJ. Different types of fearconditioned behaviour mediated by separate muclei within amygdala. Nature 1997;388:377-80.

[39] Kochanska G, Murray K, Coy KC. Inhibitory control as a contributor to conscience in childhood: from toddler to early school age. Child Development 1997;68:263-77.

[40] LaBar KS, LeDoux JE, Spencer DD, Phelps EA. Impaired fear conditioning following unilateral temporal lobectomy in humans. Journal of Neuroscience 1995;15:6846-55.

[41] LaPierre D, Braun CMJ, Hodgins S. Ventral frontal deficits in psychopathy: neuropsychological test findings. Neuropsychologia 1995;33:139-51.
[42] LeDoux J. The emotional brain. New York: Weidenfeld \& Nicolson, 1998.

[43] Levenston GK, Patrick CJ, Bradley MM, Lang PJ. The psychopath as observer: emotion and attention in picture processing. Journal of Abnormal Psychology 2000;109:373-86.

[44] Lykken DT. A study of anxiety in the sociopathic personality. Journal of abnormal and social psychology 1957;55:6-10.

[45] Lykken DT. The antisocial personalities. Hillsdale, New Jersey: Erlbaum, 1995.

[46] Newman JP. Psychopathic behaviour: an information processing perspective. In: Cooke DJ, Forth AE, Hare RD, editors. Psychopathy: theory, research and implications for society. Dordrecht, The Netherlands: Kluwer, 1998. p. 81-105.

[47] Newman JP, Patterson CM, Kosson DS. Response preservation in psychopaths. Journal of Abnormal Psychology 1987;96:145-8.

[48] Newman JP, Schmitt WA, Voss WD. The impact of motivationally neutral cues on psychopathic individuals: assessing the generality of the response modulation hypothesis. Journal of Abnormal Psychology 1997;106:563-75.

[49] O'Brien BS, Frick PJ. Reward dominance: associations with anxiety, conduct problems, and psychopathy in children. Journal of Abnormal Child Psychology 1996;24:223-40.

[50] Owen AM, Roberts AC, Polkey CE, Sahakian BJ, Robbins TW. Extra-dimensional versus intra-dimensional set shifting performance following frontal lobe excisions, temporal lobe excisions or amygdalo-hippocampectomy in man. Neuropsychologia 1991;29:9931006.

[51] Patrick CJ. Emotion and psychopathy: startling new insights. Psychophysiology 1994;31:319-30.

[52] Patrick CJ, Bradley MM, Lang PJ. Emotion in the criminal psychopath: startle reflex modulation. Journal of Abnormal Psychology 1993;102:82-92.

[53] Patterson CM, Newman JP. Reflectivity and learning from aversive events: toward a psychological mechanism for the syndromes of disinhibition. Psychological Review 1993;100:716-36.

[54] Phillips ML, Young AW, Scott SK, Calder AJ, Andrew C, Giampietro $\mathrm{V}$ et al. In: Proceedings of the Royal Society of London (B Biological Sciences) on neural responses to facial and vocal expressions of fear and disgust, vol. 265, 1998. p. 1809-17.

[55] Phillips ML, Young AW, Senior C, Brammer M, Andrews C, Calder $\mathrm{AJ}$, et al. A specified neural substrate for perceiving facial expressions of disgust. Nature 1997;389:495-8.

[56] Rahman S, Sahakian BJ, Hodges JR, Rogers RD, Robbins TW. Specific cognitive deficits in mild frontal variant frontotemporal dementia. Brain 1999;122:1469-93.

[57] Rogers RD, Everitt BJ, Baldacchino A, et al. Dissociable deficits in decision making cognition of chronic amphetamine abusers, opiate abusers, patients with focal damage to prefrontal cortex and tryptophan-depleted normal volunteers: evidence for monaminergic mechanisms. Neuropsychopharmacology 1999;20:322-39.

[58] Rolls ET. The orbitofrontal cortex and reward. Cerebral Cortex 2000;10:284-94.

[59] Rolls ET, Hornak J, Wade D, McGrath J. Emotion-related learning in patients with social and emotional changes associated with frontal lobe damage. Journal of Neurology, Neurosurgery and Psychiatry 1994;57:1518-24.

[60] Schmitt WA, Brinkley CA, Newman JP. Testing Damasio's somatic marker hypothesis with psychopathic individuals: risk takers or risk averse? Journal of Abnormal Psychology 1999;108:53843.

[61] Schneider F, Gur RE, Mozley LH, et al. Mood effects on limbic blood flow correlate with emotional self-rating: a PET study of oxygen-15 labeled water. Psychiatry Research: Neuroimaging 1995;61:26583.

[62] Schoenbaum G, Chiba AA, Gallagher M. Orbitofrontal cortex and basolateral amygdala encode expected outcomes during learning. Nature Neuroscience 1998;1:155-9. 
[63] Schoenbaum G, Chiba AA, Gallagher M. Changes in functional connectivity in orbitofrontal cortex and basolateral amygdala during learning and reversal training. Journal of Neuroscience 2000;20:5179-89.

[64] Smith SS, Newman JP. Alcohol and drug abuse-dependence disorders in psychopathic and nonpsychopathic criminal offenders. Journal of Abnormal Psychology 1990;99:430-9.

[65] Sprengelmeyer R, Young AW, Schroeder U, Grossenbacher PG, Federlein J, Buttner T, Przuntek H. In: Proceedings of the Royal Society of London (B Biological Sciences) on knowing no fear, vol. 266, 1999. p. 2451-6.

[66] Stevens D, Charman T, Blair RJR. Recognition of emotion in facial expressions and vocal tones in children with psychopathic tendencies. The Journal of Genetic Psychology 2001;162:201-11.
[67] Thorpe SJ, Rolls ET, Maddison S. The orbitofrontal cortex: neuronal activity in the behaving monkey. Experimental Brain Research 1983;49:93-115.

[68] Tiihonen J, Hodgins S, Vaurio O, Laakso M, Repo E, Soininen H, Aronen HJ, Nieminen P, Savolainen L. Amygdaloid volume loss in psychopathy. Society for Neuroscience Abstracts, 2000. p. 2017.

[69] Williamson S, Hare RD, Wong S. Violence: criminal psychopaths and their victims. Canadian Journal of Behavioral Science 1987;19:45462.

[70] Williamson S, Harpur TJ, Hare RD. Abnormal processing of affective words by psychopaths. Psychophysiology 1991;28:260 73.

[71] Wong S. Is hare's psychopathy checklist reliable without the interview? Psychological Reports 1988;62:931-4. 